\title{
Article \\ The Combination of Abscisic Acid (ABA) and Water Stress Regulates the Epicuticular Wax Metabolism and Cuticle Properties of Detached Citrus Fruit
}

\author{
Paco Romero *(D) and María Teresa Lafuente (iD \\ Department of Food Biotechnology, Institute of Chemistry and Food Technology (IATA-CSIC), Avenida Dr. \\ Catedrático Agustín Escardino 7, 46980 Paterna, Valencia, Spain; mtlafuente@iata.csic.es \\ * Correspondence: promero@iata.csic.es
}

Citation: Romero, P.; Lafuente, M.T. The Combination of Abscisic Acid (ABA) and Water Stress Regulates the Epicuticular Wax Metabolism and Cuticle Properties of Detached Citrus Fruit. Int. J. Mol. Sci. 2021, 22, 10242. https://doi.org/10.3390/ ijms221910242

Academic Editor: Víctor Quesada

Received: 23 July 2021

Accepted: 21 September 2021

Published: 23 September 2021

Publisher's Note: MDPI stays neutral with regard to jurisdictional claims in published maps and institutional affiliations.

Copyright: (c) 2021 by the authors. Licensee MDPI, Basel, Switzerland This article is an open access article distributed under the terms and conditions of the Creative Commons Attribution (CC BY) license (https:// creativecommons.org/licenses/by/ $4.0 /)$.

\begin{abstract}
The phytohormone abscisic acid (ABA) is a major regulator of fruit response to water stress, and may influence cuticle properties and wax layer composition during fruit ripening. This study investigates the effects of ABA on epicuticular wax metabolism regulation in a citrus fruit cultivar with low ABA levels, called Pinalate (Citrus sinensis L. Osbeck), and how this relationship is influenced by water stress after detachment. Harvested ABA-treated fruit were exposed to water stress by storing them at low (30-35\%) relative humidity. The total epicuticular wax load rose after fruit detachment, which ABA application decreased earlier and more markedly during fruitdehydrating storage. ABA treatment changed the abundance of the separated wax fractions and the contents of most individual components, which reveals dependence on the exposure to postharvest water stress and different trends depending on storage duration. A correlation analysis supported these responses, which mostly fitted the expression patterns of the key genes involved in wax biosynthesis and transport. A cluster analysis indicated that storage duration is an important factor for the exogenous ABA influence and the postharvest environment on epicuticular wax composition, cuticle properties and fruit physiology. Dynamic ABA-mediated reconfiguration of wax metabolism is influenced by fruit exposure to water stress conditions.
\end{abstract}

Keywords: ABA deficiency; fruit dehydration; gene expression; hormone application; Pinalate; postharvest

\section{Introduction}

Abscisic acid (ABA) was first known as abscisin II [1,2] because it was identified as a substance that regulated cotton fruit and leaf abscission. Later studies revealed its role in both biotic and abiotic stresses, and highlighted the involvement of this hormone in the regulation of the molecular mechanisms underlying the response to dehydrating conditions in plants [3]. In fruit, the participation of ABA in fruit water stress regulation has also been demonstrated in both climacteric and non-climacteric fruit [4]. More recently, a relationship between $\mathrm{ABA}$ and cuticle, the first barrier to limit water loss, has been suggested in model plants [5,6] and during fruit ripening [7-10]. ABA treatment increased wax load in Arabidopsis plants, mainly due to changes in the alkane fraction [5]. Also, ABA deficiency increased cuticle permeability and resulted in thinner cuticles during tomato leaf development [6,9]. In contrast, deficient ABA levels in tomato fruit do not have a marked effect on wax content or composition, while ABA spraying increased wax load and cuticle thickness in cherry fruit [10]. In addition, a relationship between ABA and cuticle biology has been proposed in citrus fruit $[7,8]$, although the putative ABA-mediated regulation of the cuticle composition and properties in fruit exposed to abiotic postharvest stresses remains elusive and needs to be further investigated.

The cuticle layer covers aerial plant parts and acts as the first barrier for the interaction with the environment. Given its lipophilic nature, it is a major water retention determinant in different plant organs, and is also involved in the regulation of temperature 
fluctuations and gas diffusion in addition to protection from pathogen invasion, among others [11-13]. Cuticular waxes are mixtures of cyclic compounds (e.g., triterpenoids) and aliphatic compounds (e.g., alkanes, fatty acids (FA), alcohols and aldehydes) derived from very-long-chain fatty acids (VLCFA) [14]. They can be divided into intracuticular and epicuticular waxes depending on whether their deposition is embedded in or on the cutin scaffold, respectively. Previous reports point out that fruit cuticles, and more specifically the epicuticular wax layer composition, is associated with fruit quality maintenance after harvest, in regard to susceptibility to water loss, pathogen infection, loss of firmness and the development of peel disorders [15-21].

Fruit cuticle composition is dependent on the species, and even on the cultivar, and is also determined by internal factors such as fruit development and ripening [7-9,22-34]. The effect of plant regulators, such as gibberellic acid, 2,4-dichlorophenoxy acetic acid, ethylene and 1-MCP, on epicuticular wax composition has been investigated [35-39], and a role for ABA in modulating the epicuticular wax metabolism and cuticle properties of fruit has been proposed $[7,8,10]$. Fruit cuticle composition and properties are also sensitive to external environmental factors such as humidity, temperature and light radiation $[16,40,41]$. Of these, water stress during the cultivation of or after harvesting fruit is considered the major factor that limits plant productivity and fruit quality after detachment, respectively. Cutin and intracuticular waxes have frequently been considered the main cuticle components responsible for reducing water permeability. Lately, however, the number of research works that correlate epicuticular wax load and composition with fruit water loss has grown $[7,8,18,41-43]$. Conversely, reports on how environmental humidity affects fruit cuticular wax metabolism are limited to tomatoes, grapes and pears [43-45], and whether ABA influences fruit cuticle properties as well as epicuticular wax content and composition during postharvest water stress remains elusive.

Citrus fruit is an important crop grown all over the world. As in most non-climacteric fruits, ABA plays a key role in citrus fruit development and ripening [46-52], but also in response to water stress [53-58]. Indeed, several studies have highlighted the relevance of endogenous ABA levels and an operational ABA signaling network in the molecular response of citrus fruit to dehydrating conditions determining their external fruit quality $[53,55,59]$. The availability of an impaired ABA biosynthesis mutant named Pinalate (Citrus sinensis L. Osbeck) has been crucial for such scientific progress to be made. A Pinalate orange is not a knockout mutant, but a spontaneous bud mutation that presents severe fruit-specific blockage of the carotenoid biosynthetic pathway, which results in yellow coloration, high susceptibility to postharvest dehydration and drastically low ABA levels in the flavedo (the outer colored peel part) [53,60-62]. It has also been reported that the epicuticular wax composition of this fruit differs from that in other orange cultivars with higher $A B A$ levels during fruit ripening, despite the total wax load not being affected by low ABA content in the fully mature stage [8]. These findings converge with those in other citrus cultivars, pointing to a role for $\mathrm{ABA}$ in the regulation of cuticle biology during citrus fruit maturation [7]. However, no ABA feeding experiments have been performed and the relationship between $\mathrm{ABA}$ and citrus cuticles remains elusive. In addition, the effects of $A B A$ or water stress on citrus cuticles after harvesting the fruit have never been investigated. By making the most of the markedly reduced ABA levels in Pinalate fruit, this study investigated whether ABA treatment drives changes in fruit cuticle properties as well as epicuticular wax load and composition after detachment, and if these modifications are influenced by exposure to water stress conditions during postharvest storage. We addressed these questions by comparing the wax composition as well as cuticle permeability and thickness, together with the fruit weight loss and firmness measurements, of the Pinalate fruit, either treated or not with ABA and left under high relative humidity (RH) or postharvest water stress conditions that favor fruit dehydration. Correlation analyses allowed us to identify the relations among ABA content, wax constituents, cuticle properties and fruit quality maintenance during storage. To dig more further into the molecular 
mechanisms underlying these relations, an expression analysis of the key genes involved in the biosynthesis and transport of wax components was performed.

\section{Results}

\subsection{Effects of $A B A$ and Water Stress on Wax Content and Wax Fraction Distribution}

Pinalate oranges were treated, or not, with $1 \mathrm{mM}$ ABA solution before being stored under the control $(90-95 \% \mathrm{RH})$ or water stress $(30-35 \% \mathrm{RH})$ environmental conditions. As shown in Figure 1, the total wax content in Pinalate increased by two-fold in the first week of storage and slightly decreased thereafter regardless of the environmental conditions. ABA treatment reduced the total wax load increment observed by 1 week, which was more marked under the dehydrating conditions. By 3 weeks, this trend was observed only in the fruit stored under the postharvest water stress conditions (Figure 1).

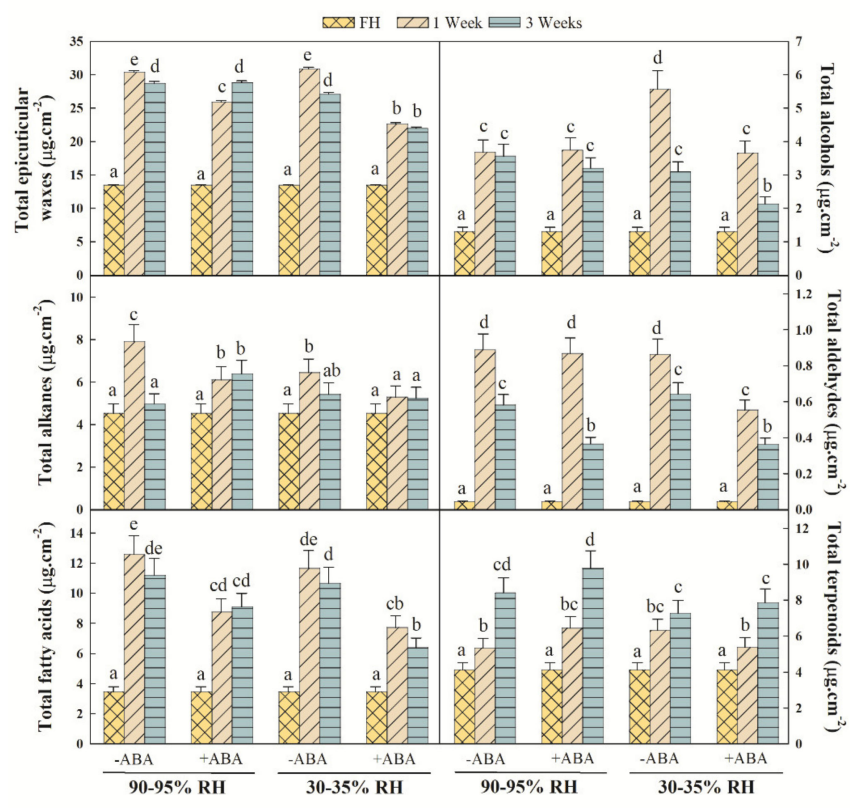

Figure 1. Effect of ABA and water stress on the total epicuticular wax and individual fractions content in Pinalate fruit. The effect of ABA $(1 \mathrm{mM})$ treatment was evaluated together with the influence of high (90-95\%) or low (30-35\%) RH conditions on the total content $\left(\mu \mathrm{g} . \mathrm{cm}^{-2}\right)$ of epicuticular wax and the individual fractions up to 3 weeks of leaving Pinalate fruit at $20^{\circ} \mathrm{C}$. Bars are means $\pm \mathrm{SD}$ of four replicates per condition. FH: Freshly harvested fruit. For each panel, the different letters above the bars indicate significant $(p<0.05)$ differences among conditions according to an ANOVA analysis followed by a Tukey test $(p<0.05)$.

Noticeable responses to the total content of five major wax fractions were detected in response to $\mathrm{ABA}$ treatment and the postharvest water stress conditions. These fractions were alkanes $\left(\mathrm{C}_{22}-\mathrm{C}_{34}\right)$, FA $\left(\mathrm{C}_{12}-\mathrm{C}_{28}\right)$, alcohols $\left(\mathrm{C}_{22}-\mathrm{C}_{32}\right)$, aldehydes $\left(\mathrm{C}_{24}, \mathrm{C}_{26}\right)$ and terpenoids $\left(\mathrm{C}_{15}, \mathrm{C}_{29}\right.$ and $\left.\mathrm{C}_{30}\right)$ (Figure 1$)$. The total alkane content increased by 1 week during the control or dehydrating fruit storage. Independently of the water stress environment, ABA treatment reduced this increase. Similarly, the increase observed in the total FA content after harvest was reduced by applying ABA to Pinalate fruit, regardless of storage conditions. In contrast, an effect of ABA on alcohol content was only observed in water-stressed fruit. Thus, the alcohol accumulation pattern in the Pinalate fruit under water stress remained after the ABA treatment, but the total achieved content lowered by about $30 \%$. Aldehyde content increased by about nine-fold 1 week after fruit detachment and decreased thereafter during storage under both the control and water stress conditions. A major effect of ABA on aldehyde content was observed in the Pinalate fruit exposed to postharvest water stress, as this fraction accumulation lowered by about $25 \%$ and $30 \%$ by week one and week three, respectively, compared to untreated fruit. The total terpenoid 
content also increased after harvesting the fruit. No differences in terpenoid accumulation were observed between the ABA-treated and untreated fruit stored at either high or low $\mathrm{RH}$, but the total content achieved in the ABA-treated fruit was higher at high $\mathrm{RH}$ than during water stress storage.

The effects of ABA treatment on wax composition were dependent on exposure to postharvest water stress and storage duration (Figure 2). At harvest, the most abundant components were alkanes $(33.7 \%)$, followed by terpenoids (30.6\%), FA (25.7\%), alcohols $(9.7 \%)$ and aldehydes $(0.3 \%)$. In response to harvest, alkane abundance lowered, and a transitory decrease in terpenoids was observed by 1 week. The percentage of FA and aldehydes increased 1 week after storage and remained almost steady thereafter under either environmental condition (Figure 2). Nevertheless, by 1 week of postharvest water stress, the abundance of alkanes and FA was lower, and that of alcohols and terpenoids was higher than in the fruit left at high RH. By 3 weeks, however, these trends were inversed and postharvest water stress brought about a decrease in terpenoid abundance and an increase in the alkane proportion. Hormone application enhanced the initial decrease in alkane abundance in the Pinalate fruit stored at high $\mathrm{RH}$, while the opposite was found under the fruit-dehydrating condition. ABA treatment slightly modified the alcohol proportion by 1 week under either the control or postharvest water stress storage. The increase in the FA proportion after fruit detachment was attenuated by ABA application, and was more marked by 3 weeks under the fruit-dehydrating condition. Terpenoid abundance was increased by ABA independently of storage and period. However, the effects of ABA on the aldehyde proportion varied depending on postharvest water stress exposure and duration (Figure 2).
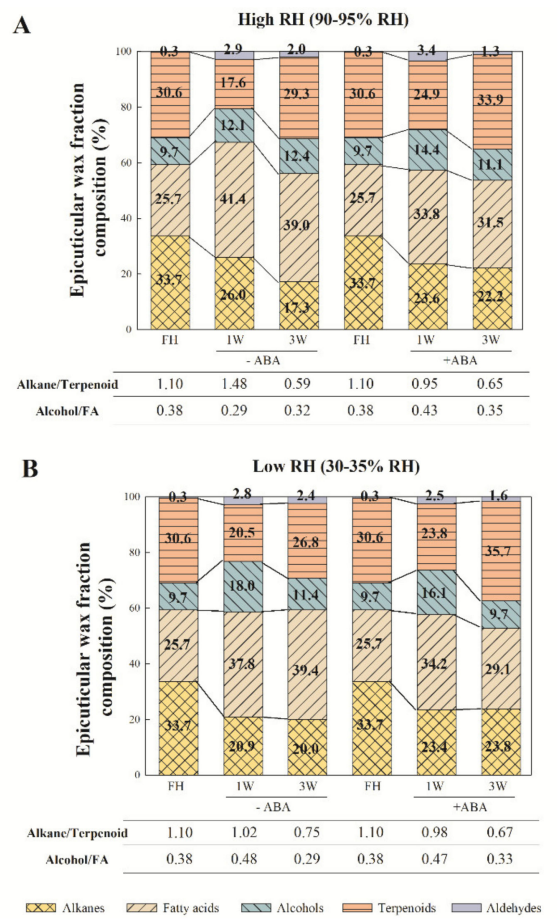

Figure 2. Effect of $A B A$ and water stress on the proportion of epicuticular wax fractions in Pinalate fruit. The effect of ABA $(1 \mathrm{mM})$ treatment on the percentage (\%) of epicuticular wax fractions by 1 and 3 weeks (W) of Pinalate fruit storage at $20^{\circ} \mathrm{C}$ was evaluated together with the influence of the (A) high (90-95\%) or (B) low (30-35\%) RH conditions. FH: Freshly harvested fruit. The values on the bars indicate the percentage of each fraction. The alkane/terpenoid and alcohol/FA ratios are indicated per condition. The same legend is used for panels $(\mathbf{A}, \mathbf{B})$.

As a result of these changes, the alkane/terpenoid and alcohol/FA ratios, which are inversely related to fruit water retention, were modified in response to ABA application 
and/or fruit exposure to postharvest water stress. The alkane/terpenoid ratio transitorily increased 1 week after fruit detachment when stored at high $\mathrm{RH}$, but continuously decreased in response to ABA treatment under this condition. In contrast, this ratio continuously lowered in the fruit exposed to postharvest water stress, and no influence of ABA was observed. The alcohol/FA ratio slightly varied during fruit storage. The effects of $\mathrm{ABA}$ were also minor. If any, an increase in the alcohol/FA ratio was observed in the ABA-treated fruit stored for 1 week at high RH compared to the untreated fruit (Figure 2).

\subsection{Epicuticular Wax Composition Analysis}

Heptacosane $\left(C_{27}\right)$, nonacosane $\left(C_{29}\right)$ and hentriacontane $\left(C_{31}\right)$ were the most abundant long-chain alkanes in Pinalate fruit, irrespective of $\mathrm{ABA}$ treatment and storage conditions (Figure $3 \mathrm{~A}, \mathrm{E})$. The accumulation of tricosane $\left(\mathrm{C}_{23}\right)$ and pentacosane $\left(\mathrm{C}_{25}\right)$ was also noticeable among the odd-chain alkanes. Even-chain-length compounds $\left(\mathrm{C}_{22}-\mathrm{C}_{34}\right)$ were a minority among alkane components and were not consistently detected under the assayed experimental conditions. The accumulation profiles of the odd long-chain alkanes were differently affected by ABA treatment depending on exposure or not to postharvest water stress. Some differences in their accumulation patterns were found when comparing high $\mathrm{RH}$ and fruit-dehydrating conditions. Thus, ABA treatment lowered the increments detected for the odd long-chainlength compounds by 1 week at high and low RH. In contrast, hormone application increased these compounds by 3 storage weeks at high $\mathrm{RH}$, but did not modify their contents in the water-stressed fruit during this period. Their accumulation was higher at high rather than low RH by 1 week, but no differences caused by environmental conditions were found after 3 storage weeks in the untreated fruit (Figure 3A,E).

At harvest, the most abundant FA were lignoceric $\left(C_{24}\right)$ and cerotic $\left(C_{26}\right)$ acids, followed by palmitic $\left(\mathrm{C}_{16}\right)$ and stearic $\left(\mathrm{C}_{18}\right)$ acids. All these compounds, as well as montanic acid $\left(\mathrm{C}_{28}\right)$, increased after harvesting fruit, but specific accumulation patterns were found in response to $\mathrm{ABA}$ application in addition to the storage period and conditions. Thus, the content of both lignoceric and cerotic acids increased during storage, and ABA treatment attenuated their accumulation independently of the environment (Figure 3B,F). In contrast, palmitic and stearic acids increased in response to ABA application by 1 week, but only at high RH. This effect was lost by 3 weeks. No effects of ABA on these FA were detected under the fruit-dehydrating condition by 1 week, but hormone treatment reduced their accumulation by 3 weeks. Similarly, exogenous ABA did not modify the montanic acid content under the water stress conditions, but its accumulation lowered at high RH by 1 and 3 weeks. In addition, hormone treatment reduced montanic acid accumulation under the fruit-dehydrating conditions by 3 weeks (Figure 3F).

The most abundant primary alcohols were docosanol $\left(\mathrm{C}_{22}\right)$, tetracosanol $\left(\mathrm{C}_{24}\right)$ and pentacosanol $\left(C_{25}\right)$. Triacontanol $\left(C_{30}\right)$ and dotriacontanol $\left(C_{32}\right)$ were not detected at harvest, but accumulated during storage (Figure $3 \mathrm{C}, \mathrm{G}$ ). All these compounds increased after harvest independently of the environmental conditions, but the effect of $\mathrm{ABA}$ treatment on the content of each compound depended on RH and storage duration. Thus, docosanol content, the most abundant alcohol in Pinalate fruit, was not affected by ABA treatment at high $\mathrm{RH}$, but lowered under water stress by 1 week. In contrast, hormone application decreased the docosanol content by 3 weeks regardless of the storage conditions. Our analyses identified two aldehydes, tetracosanal $\left(C_{24}\right)$ and hexacosanal $\left(C_{26}\right)$, which increased after detachment, but did not show any remarkable differences between storage conditions (Figure 3C,G). ABA decreased their accumulation by 3 weeks. This trend was evident in tetracosanal content by 1 week, but only under postharvest water stress. 

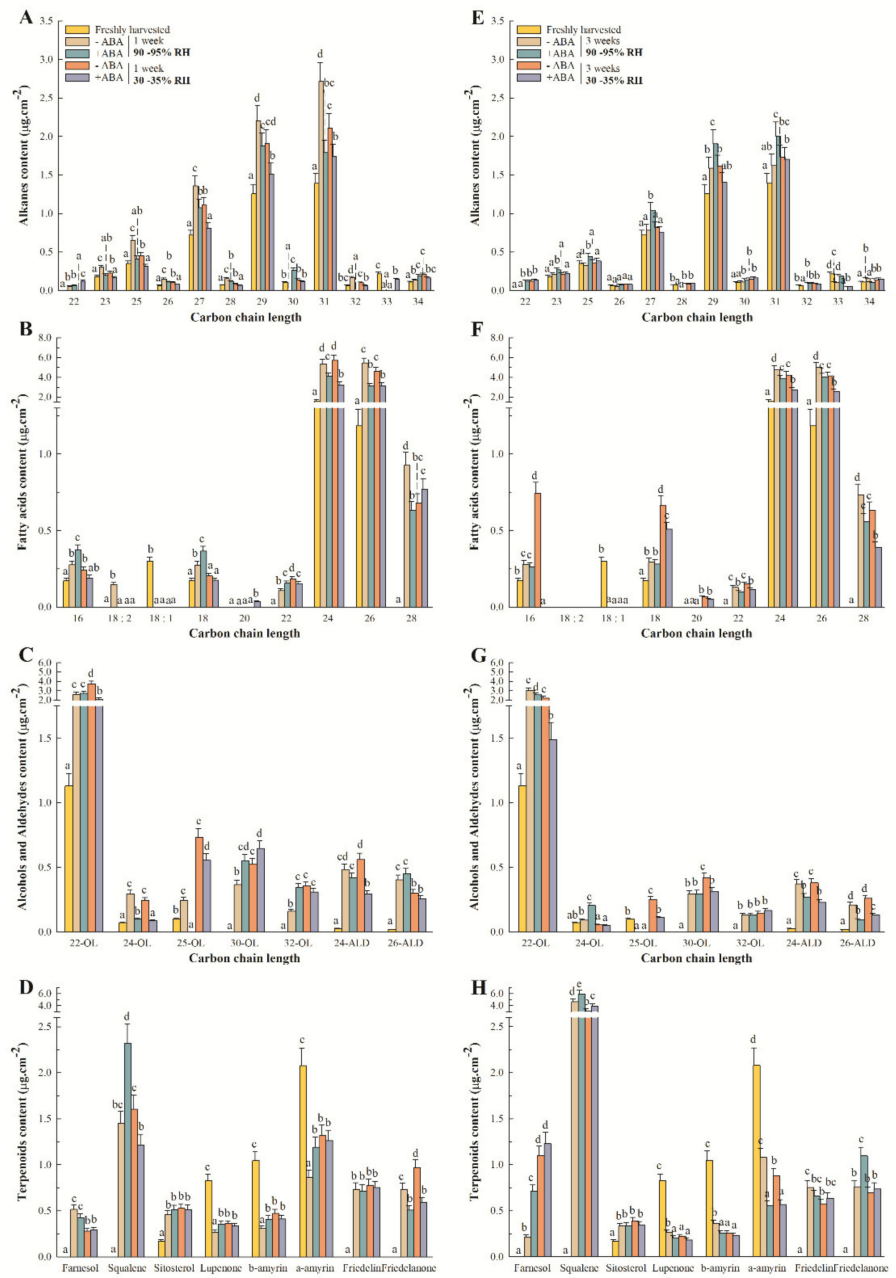

Figure 3. Effect of ABA and water stress on epicuticular wax constituents during Pinalate fruit storage. The effects of ABA $(1 \mathrm{mM})$ treatment on the content of the epicuticular wax components were evaluated together with the influence of high (90-95\%) or low (30-35\%) RH by 1 (A-D) and 3 (E-H) weeks at $20^{\circ} \mathrm{C}$. (A,E) Alkanes; (B,F) fatty acids; (C,G) alcohols and aldehydes; and (D,H) terpenoids. Bars are the means \pm SD of four replicates per condition. Different letters above the bars indicate significant $(p<0.05)$ differences among conditions according to an ANOVA analysis followed by a Tukey test $(p<0.05)$ for each component and storage time separately.

Among terpenoids, only $\alpha$ - and $\beta$-amyrins, lupenone and sitosterol were detected at harvest, although farnesol, squalene, friedelin and friedelanone accumulated thereafter (Figure 3D,H). Lupenone, $\alpha$ - and $\beta$-amyrins decreased in Pinalate fruit in response to fruit detachment and independently of storage conditions. The other terpenoids, however, increased after harvest. The response to ABA application was diverse among these compounds and depended on RH and storage duration. Sitosterol, friedelin and farnesol contents did not vary after ABA treatment, except for farnesol content, which increased in the ABA-treated fruit exclusively when stored for 3 weeks at high RH. Squalene content, the most abundant terpenoid in Pinalate fruit, was inversely regulated by ABA application between the control and fruit-dehydrating conditions by 1 week. By 3 weeks, its content had considerably increased and ABA induced its accumulation regardless of the environmental conditions.

\subsection{Variations in Cuticle Properties and Fruit ABA Content, Firmness and Weight Loss}

The ABA content in Pinalate fruit slightly increased after detachment irrespective of storage conditions. Likewise, exogenous ABA application increased the hormone content 
in both the fruit stored at high $\mathrm{RH}$ and under postharvest water stress by about fivefold (Figure 4A). Cuticle thickness continuously decreased after detachment. By 1 week, this decrease was slight under postharvest water stress, but more drastic at high $\mathrm{RH}$ (Figure 4B). When the experiment ended (3 weeks), cuticles were thicker in the fruit left under the postharvest dehydration conditions than those left at high RH. ABA treatment did not significantly affect these patterns independently of storage. Nevertheless, the thinnest cuticles were those from the ABA-treated fruit stored for 3 weeks at high RH. Cuticle permeability (estimated as the cuticle transpiration rate) barely changed in response to the dehydrating environment and/or ABA treatment. In fact, an increase in cuticle permeability was detected only in the ABA-treated fruit stored for 3 weeks at high $\mathrm{RH}$ (Figure 4C). Cumulative weight loss per surface area continuously increased in Pinalate fruit during storage, and it was about four-fold higher when fruit were kept under the postharvest dehydration conditions (Figure 4D). A slight, but statistically significant, reduction in cumulative weight loss was observed by 1 and 3 weeks in the ABA-treated fruit versus the untreated fruit left under water stress. Fruit firmness remained unchanged by 1 week after detachment and decreased thereafter in the fruit left at high $\mathrm{RH}$, and no effect of ABA was observed. Postharvest water stress, however, brought about a marked decrease in fruit firmness regardless of ABA treatment (Figure 4E).
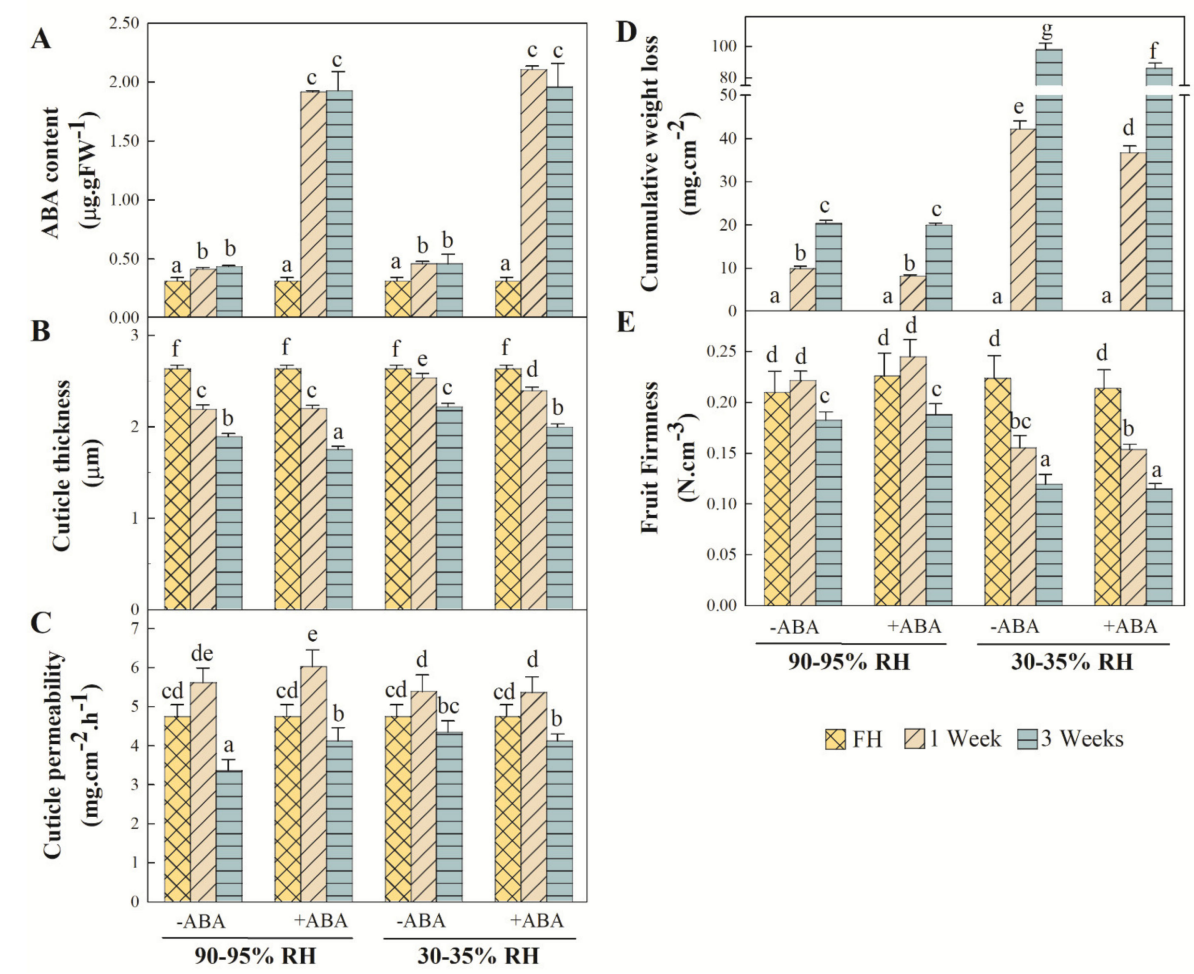

Figure 4. Effect of ABA and water stress on cuticle properties and fruit physiological parameters in Pinalate fruit. (A) ABA content is expressed as g per $g$ of fresh weight (FW) of the flavedo. Bars are the means \pm SD of three replicates of five fruit each. (B) Cuticle thickness. Bars represent the means \pm SD of about 50 measurements for all three biological replicates analyzed per condition. (C) Cuticle permeability. Bars are the means $\pm S D$ of three replicates per condition. (D) Cumulative weight loss of Pinalate fruit calculated as fruit weight loss per surface area. Bars are the means \pm SD of three replicates of 10 fruit each. (E) Fruit firmness was determined according to the intact fruit compression resistance load $(\mathrm{N})$ and normalized by fruit size $\left(\mathrm{cm}^{3}\right)$. Bars indicate the means \pm SD of three replicates of 10 fruit each. For each studied parameter, different letters indicate the statistical $(p<0.05)$ differences in all the conditions together according to an ANOVA analysis followed by a Tukey test $(p<0.05)$. 


\subsection{Relationships between ABA Content, Cuticle Composition and Properties and Fruit Physiology}

In order to elucidate the relationships among the experimental conditions as regards ABA application and exposure to postharvest water stress, the total epicuticular wax content, the content of each wax fraction, ABA levels, cuticle thickness and permeability, and fruit weight loss and firmness were used to perform a cluster analysis (Figure 5A). According to the HCA, the freshly harvested (FH) and stored fruit were the most clearly discriminated groups. Later, samples were clustered in a storage-period-dependent manner. During each storage period, the samples that were grouped depending on exposure to postharvest water stress followed a distinction between the ABA-treated and untreated fruit. The dendrogram corresponding to cuticle composition and properties, ABA content and fruit physiological parameters can be divided into three major groups. The first includes two subclades composed of cuticle thickness, permeability and fruit firmness in addition to total alkane content. Second, ABA content, total terpenoids and fruit weight loss were clustered together. The last group contained the total wax load and the total content of all the cuticle fractions, except alkanes and terpenoids (Figure 5A).

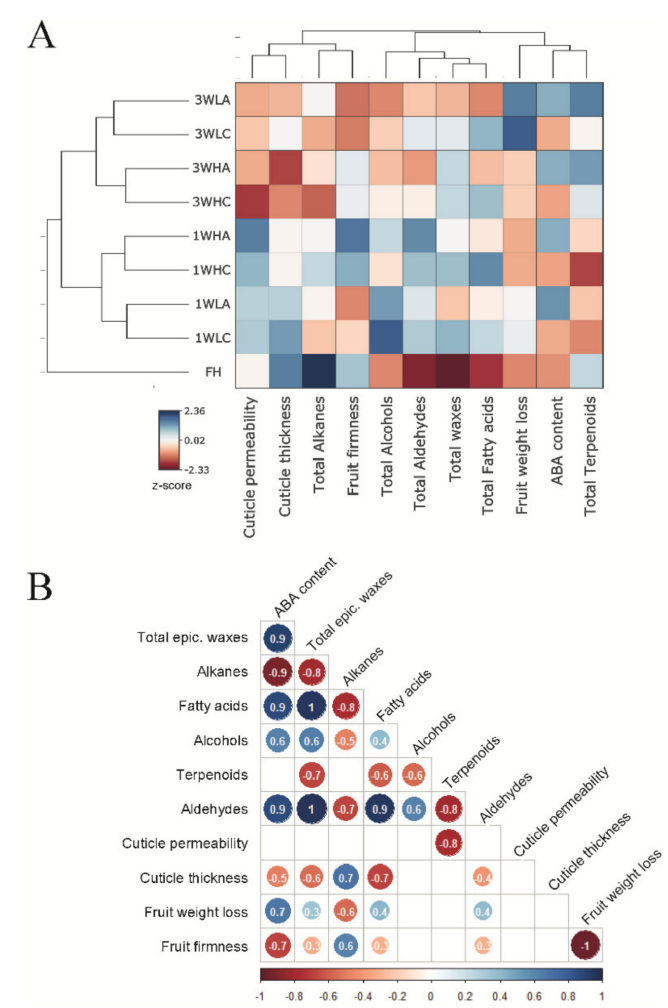

Figure 5. Clustering and correlation analyses of epicuticular wax composition, ABA content, cuticle properties and fruit physiological parameters in Pinalate fruit. (A) Hierarchical clustering analysis of the Pinalate fruit left at high $(\mathrm{H}, 90-95 \%)$ or low (L, 30-35\%) RH for 1 week or 3 weeks (W), and treated (A, ABA) or not $(\mathrm{C}$, control) with $1 \mathrm{mM}$ ABA, based on the chemical composition of their epicuticular wax layer, ABA content, cuticular properties and fruit physiology. The colors in the heatmap indicate the $\mathrm{z}$-score value for each parameter and condition according to the scale in the legend. (B) Correlation matrix among the abundance of individual epicuticular wax fractions, ABA content, cuticle properties and fruit physiological parameters in the Pinalate fruit left under the above-described conditions. Numbers indicate the regression coefficient value, and only the statistically significant ones are colored according to the scale in the legend.

The effects of ABA application and exposure to water stress after fruit detachment on cuticle composition and properties, as well as on fruit weight loss and firmness, were further studied by a statistical correlation analysis (Figure 5B). ABA content correlated 
positively with total epicuticular wax $(r=0.9)$, FA $(r=0.9)$, alcohol $(r=0.6)$ and aldehyde $(r=0.9)$ proportions and fruit weight loss $(r=0.7)$. Inversely, ABA content negatively correlated with alkane proportion $(r=0.9)$, cuticle thickness $(r=-0.5)$ and fruit firmness $(\mathrm{r}=-0.7)$. The alkane proportion showed a negative correlation with fruit weight loss $(\mathrm{r}=-0.6)$, but correlated positively with cuticle thickness $(\mathrm{r}=0.7)$ and fruit firmness $(r=0.6)$. Inversely, FA and aldehyde abundance related positively to fruit weight loss $(r=0.4)$, but negatively to fruit firmness $(r=-0.3)$ and cuticle thickness $(r=-0.7$ and $r=-0.4$, respectively). The percentage of terpenoids was the only wax fraction to show a correlation with cuticle permeability $(\mathrm{r}=-0.8)$ (Figure $5 \mathrm{~B})$. These relationships agreed with the correlations found among the different epicuticular wax fractions as alkanes negatively correlated with FA and aldehydes $(r=-0.8$ and $r=-0.7$, respectively) and FA related positively to the aldehyde proportion $(r=0.9)$. In turn, fruit weight loss negatively related to fruit firmness $(r=-0.97)$ (Figure $5 B$ ).

\subsection{Effects of ABA and Water Stress on the Transcriptional Regulation of Epicuticular Wax-Related Genes}

In order to further investigate a putative epicuticular wax metabolism reconfiguration mediated by ABA and/or exposure to postharvest dehydration, a transcriptional analysis on key genes involved in epicuticular wax biosynthesis, transport and regulation was performed (Figure 6). The expression of CSCER3, involved in the synthesis of alkanes, remained almost steady during fruit storage at high $\mathrm{RH}$, but significantly decreased with exposure to fruit dehydration. The effect of ABA on CsCER3 accumulation depended on the storage environment. Indeed, ABA treatment did not statistically affect CsCER3 expression at high $\mathrm{RH}$, but counteracted the decreased transcript accumulation pattern observed under water stress in the untreated fruit. The expression levels of CSCER4/FAR3, which encode an FA reductase involved in the synthesis of primary alcohols, transitorily peaked by 1 week at high $\mathrm{RH}$, but continuously lowered when fruit were exposed to water stress after detachment. ABA treatment generally reduced the accumulation of transcripts regardless of storage conditions, although this effect was more marked at high $\mathrm{RH}$. The gene expression levels of CsSQS, involved in squalene synthesis, increased after harvest, independently of storage, but this increment was transitory when fruit were left in a dehydrating environment. Independently of being exposed or not to postharvest water stress, ABA application reduced CSSQS transcript accumulation throughout the storage period. CsCER6/KCS6, which encode a $\beta$-ketoacyl-CoA synthase involved in the synthesis of VLCFA precursors, remained steady in the fruit left at high $\mathrm{RH}$, but dropped by three-fold when fruit were exposed to dehydration for 3 weeks. The effects of ABA on the accumulation of CsCER6/KCS6 transcripts differed depending on storage, because hormone treatment lowered the gene expression levels at high $\mathrm{RH}$, but slightly increased the transcript levels by 3 weeks under postharvest water stress. Epicuticular wax transporters Cs $A B C G 11 / W B C 11$ and CsABCG12/WBC12 were similarly regulated in regard to $A B A$ and the water stress response. Both transporters were continuously induced during storage at high $\mathrm{RH}$, and remained almost steady after an initial increase by 1 week when fruit were exposed to water stress. Transcript levels were also lower after water stress storage. 

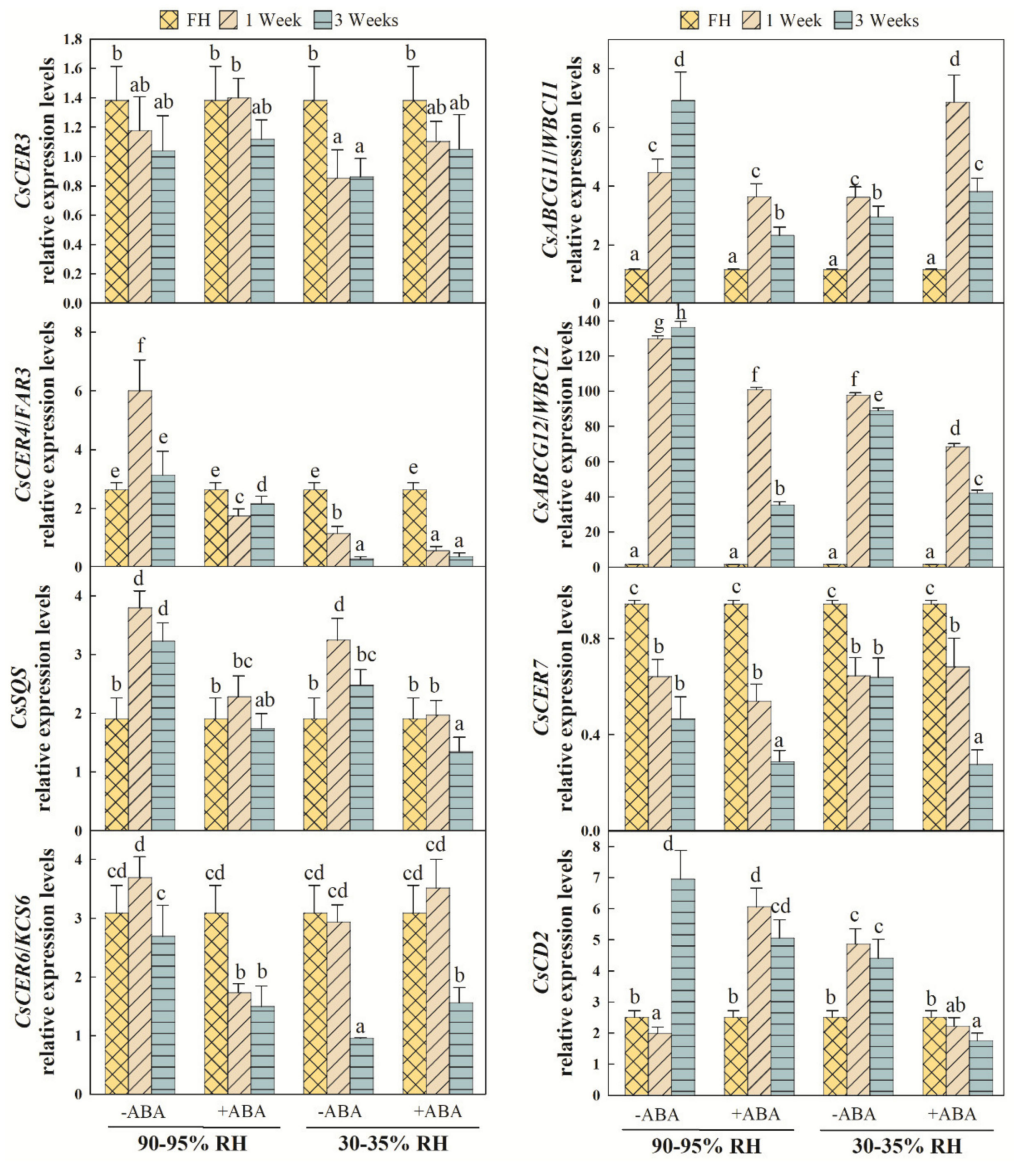

Figure 6. Effect of $\mathrm{ABA}$ and water stress on the transcriptional regulation of epicuticular wax metabolism. Relative expression levels of the genes related to the transcriptional (CsCD2) and posttranscriptional (CsCER7) regulation of the biosynthesis (CsCER6/KCS6, CsCER3, CsCER4 and CsSQS) and transport (CsABCG11/WBC11, CsABCG12/WBC12) of the wax components in the Pinalate fruit treated (+ABA) or not (-ABA) with ABA (1 mM), and left at high (90-95\%) or low (30-35\%) RH for up to 3 weeks at $20^{\circ} \mathrm{C}$. Gene expression values are expressed as fold change levels of all conditions as compared to the freshly harvested $(\mathrm{FH})$ fruit. Values are the means of three biological replicates per condition. Different letters indicate statistical $(p<0.05)$ differences among all the conditions together according to an ANOVA analysis followed by a Tukey test $(p<0.05)$ for each gene individually.

After ABA treatment, the CsABCG11/WBC11 and CsABCG12/WBC12 expression levels peaked by 1 week regardless of the water stress exposure. It is worth noting that $A B A$ enhanced CsABCG11/WBC11 accumulation, but lowered that of CSABCG12/WBC12 under water stress compared to the untreated fruit. The expression levels of the CsCER7 posttranscriptional regulator bottomed down in response to harvest by 1 week and remained steady thereafter independently of the environment. ABA also repressed transcript accumulation by 3 weeks at either high or low RH. Last, the CsCD2 transcription factor expression showed a significant influence for both ABA and postharvest water stress exposure. Thus, CsCD2 gene expression transiently decreased by 1 week to sharply increase thereafter at high $\mathrm{RH}$, but increased in response to fruit dehydration in the first week of storage. In addition, $\mathrm{ABA}$ treatment counteracted the initial decrease in gene expression at high $\mathrm{RH}$, while inhibiting the increment in the $C s C D 2$ transcript levels when fruit were exposed to water stress (Figure 6).

\section{Discussion}

The cuticle is extremely sensitive to surrounding fluctuations and, specifically, the epicuticular wax composition adjusts in response to environmental signals [63-66]. The 
study of the ABA-mediated regulation of cuticle properties and composition has been a hot research topic for years in both Arabidopsis model plants and several horticultural crops. However, research into this relationship in fruit has been limited to tomatoes, cherries and citruses [7-10]. In addition, whether ABA regulates epicuticular wax composition after fruit detachment or if such effects depend on fruit being exposed to dehydrating conditions remains elusive, despite ABA being the main hormone to regulate the fruit water stress response [4]. Moreover, cuticle properties influence fruit water loss and, hence, fruit quality during postharvest $[11,15,16,40,66]$. In citrus fruit, the association between epicuticular waxes and fruit water retention has been established $[7,67]$. There are also reports that moderated water stress (70-75\% RH) during postharvest causes fruit dehydration and triggers ABA-mediated signals in order to reduce fruit water loss and, hence, alleviate external quality loss [53]. An important advance contributed by the present research is that the effect of increasing the fruit ABA content by hormone feeding on fruit epicuticular wax metabolism was studied in combination with exposure to water stress, which increased fruit weight loss after detachment. To this end, Pinalate, an ABA-biosynthesis-impaired citrus mutant cultivar, that displays sharply reduced hormone levels in the flavedo, was treated with ABA and exposed to postharvest water stress.

The major finding in the present work is that ABA treatment dynamically modifies the epicuticular wax composition and metabolism of Pinalate fruit after detachment depending on whether the fruit is exposed, or not, to postharvest dehydration, and also on the duration of stress. This is deduced from the results, which showed that the increased total epicuticular wax load observed after fruit detachment was diminished by ABA treatment only after 1 week at high $\mathrm{RH}$, but more markedly and during complete storage (up to 3 weeks) under fruit water stress (Figure 1). These ABA application effects were also evident on the total contents of individual wax fractions, such as alkanes, alcohols and aldehydes, and best-fitted the accumulation profile of FA, but not terpenoids (Figure 1). The compositional data analysis of each wax fraction further supported our statement as different responses to ABA treatment were observed by 1 and 3 weeks, which depended on the storage conditions for most individual wax components (Figure 3). In this context, the effects of ABA treatment on modifying wax composition were more evident when focusing on the proportion of each separate fraction. The most important changes can be summarized as attenuated FA accumulation and the enhanced increase in the terpenoid proportion in the ABA-treated fruit compared to those untreated, regardless of the postharvest storage conditions (Figure 2). In fact, even though ABA content correlated with the total epicuticular wax load and to all the wax fraction abundances, except terpenoids (Figure 5B), the contents of several terpenoid compounds, such as squalene, lupenone, friedelanone and $\alpha$ - and $\beta$-amyrins, were regulated by ABA application (Figure 3D,H). However, this ABA-mediated regulation differed between high $\mathrm{RH}$ and water stress, and also between 1 and 3 storage weeks, which probably modified their abundance in this fraction, and might influence both cuticle permeability and fruit weight loss [36,68-71]. This agrees with the fact that ABA treatment increased cuticle permeability by 3 weeks at high $\mathrm{RH}$, but reduced Pinalate fruit weight loss during postharvest dehydration (Figure 4C,D).

Currently, research into the effects of postharvest water stress on wax composition is limited to pear and tomato; Korla pear wax content and composition adjusts to different RH storage conditions, while the wax chemical profile of tomato fruit, including a long-shelf-life cultivar, does not modify in response to water stress after harvesting the fruit $[43,45]$. In the present study, orange fruit displaying sharply low ABA levels showed increased total wax load after fruit detachment, without influence from the water stress of the postharvest environment. On the contrary, the total contents of the alkanes and alcohols in Pinalate were influenced by storage conditions by 1 week (Figure 1). Furthermore, under the postharvest dehydration conditions, the abundance of alkanes and FA was lower, and that of alcohols and terpenoids was higher after this period. Moreover, by 3 weeks, these trends were reversed as postharvest water stress brought about a decrease in terpenoid abundance and an increase in alkane proportion. Consequently, the alkane/terpenoid and 
alcohol/FA ratios varied with both $\mathrm{RH}$ and storage duration (Figure 2). Several research works converge with the idea that the proportion of hydrocarbons (i.e., alkanes), unlike terpenoids and cyclic compounds, is the most effective fraction for water retention. Thus, a drop in the alkane/terpenoid ratio would increase the proportion of amorphous structures and, consequently, cuticle permeability and/or fruit water loss [36,68-72]. Results from our chemical analysis partially agree with these findings, as the alkane/terpenoid ratio dropped in response to water stress by 1 week when a four-fold increase in cumulative fruit weight loss was noted (Figures 2 and 4). Notwithstanding, ABA application lowered the alkane/terpenoid ratio after 1 week of storage at high $\mathrm{RH}$, while no differences in fruit weight loss or cuticle permeability were found between the ABA-treated and untreated fruit left under this condition. Conversely, fruit weight loss statistically decreased as a result of $\mathrm{ABA}$ treatment under postharvest dehydration, but the alkane/terpenoid ratio in these fruit barely changed compared to the untreated fruit (Figures 2 and 4). Besides, a higher alcohol/FA ratio has been associated with greater fruit weight loss [45], which agrees with our results showing that the dehydrating condition increased the alcohol/FA ratio compared to remaining at a high RH for 1 week. Minor ABA effects on this ratio were observed. If any, ABA treatment increased the alcohol/FA ratio by about $50 \%$ by 1 week at high $\mathrm{RH}$, which was due mainly to a reduction in FA abundance (Figures 2 and 4). Altogether, the results presented herein partially diverge from the idea of a straight correlation between these ratios and the fruit cuticle permeability and susceptibility to weight loss. In addition, the attenuated total epicuticular wax accumulation as a result of ABA treatment after Pinalate fruit detachment contrasts with not only reported increments in wax content in cherry fruit after on-vine spraying with ABA [10], but also with the fact that ABA-deficient tomato fruit mutants do not display differences in total wax content compared to their parental lines [9]. The epicuticular wax load of the fully mature Pinalate fruit did not differ from that in other citrus cultivars with higher endogenous ABA contents [8]. In this context, we should bear in mind that Pinalate fruit presents low ABA levels in the peel, but it is not a knockout mutant, and ABA treatment applied to orange fruit with higher ABA levels has not led to changes in either susceptibility to fruit weight loss or the molecular mechanisms underlying fruit dehydration, probably because endogenous levels of the hormone might suffice to trigger cellular processes to cope with stress [53,60,62]. These facts indicate that the ABA-mediated regulation of cuticle metabolism is species-/cultivar-dependent, and other intrinsic factors, such as endogenous hormone levels, climacteric or non-climacteric fruit ripening and/or fruit sensitivity to hormone application when on-vine or detached, might influence this relationship.

The expression profiles of the key genes involved in the synthesis, transport and transcriptional regulation of epicuticular waxes generally support the notion that the effect of $\mathrm{ABA}$ on this metabolism depends on both $\mathrm{RH}$ and the duration of the imposed water stress after harvesting the fruit. Indeed, the expression patterns of all the studied genes were somewhat influenced by ABA. Despite the lack of statistical differences in the CsCER3 levels between the ABA-treated and untreated fruit stored in either RH environment, it was noteworthy that $\mathrm{ABA}$ application alleviated the diminished transcript accumulation of this gene, which is involved in alkane synthesis during postharvest dehydration (Figure 6). However, the effect of ABA decreasing the expression of CsSQS and CsWBC12, both involved in the synthesis of squalene and terpenoid precursors and in transporting cuticular components to the extracellular matrix, respectively, was observed regardless of storage duration and conditions. This was also true for CsCER7, a post-transcriptional regulator, accumulation despite the effect of $\mathrm{ABA}$ decreasing gene expression depending on storage duration, since it was only observed by 3 weeks (Figure 6). In contrast, the effects of $\mathrm{ABA}$ on CsCER4, CsCER6, CsWBC11 and CsCD2 regulation were dependent on both exposure to postharvest dehydration and stress duration. Moreover, the expression of the CsWBC11 transporter and the CsCD2 transcription factor was affected by ABA via a trend that did not vary between 1 and 3 weeks when fruit were stored under the dehydrating condition, but it differed between the storage periods at high RH. Inversely, CsCER6 and 
CSCER4, respectively involved in the synthesis of VLCA and primary alcohols, showed an ABA effect that did not depend on storage period at high RH, but varied between 1 and 3 weeks when fruit were exposed to water stress. Altogether these data reflect that the ABA-mediated transcriptional regulation of epicuticular wax metabolism is complex and depends on the ABA treatment and postharvest water stress combination, and this relation may change as stress exposure progresses.

Our results indicate that detachment from tree causes the accumulation of epicuticular wax load in citrus fruit with low ABA levels, and that applying ABA after harvesting the fruit attenuates this increase. This ABA-related effect substantially increases in fruit exposed to water stress during postharvest. In turn, this research reveals that ABAdriven changes in the epicuticular wax chemical profile and metabolism depend firstly on storage duration, and in a minor extent on the exposure to water stress conditions during postharvest. Therefore, this data provides clues for industrial wax synthesis purposes and improves the knowledge on the ABA-dependent regulation of cuticular wax metabolism in fruits.

\section{Materials and Methods}

\subsection{Fruit Materials and Experimental Design}

Pinalate (Citrus sinensis L. Osbeck) sweet orange fruit were harvested from five adult trees grown in experimental orchards in the fully mature ripening stage according to the normal cultural practices applied by the Citrus Germplasm Bank at the IVIA (Moncada, Valencia) in Spain. Fruit were immediately delivered to the laboratory and those without peel damages or visual defects and with an average diameter of $6 \mathrm{~cm}$ were assigned to two groups. Fruit were treated with either ABA by dipping them for $1 \mathrm{~min}$ in an aqueous $1 \mathrm{mM}$ ABA solution containing $0.7 \%$ ethanol to dissolve the hormone (treatment group, $+\mathrm{ABA}$ ) or water containing $0.7 \%$ ethanol (control group, $-\mathrm{ABA}$ ) following the same procedure. ABA treatment was repeated 2 weeks after harvest to ensure high ABA levels throughout the experiment. This dosage was selected according to previous experiments performed by our group which showed the effect of exogenous ABA on the response of citrus fruit to stressful conditions $[53,55,59]$. Both sets of fruit were divided into two subgroups and stored in the dark at $20{ }^{\circ} \mathrm{C}$ for up to 3 weeks in incubation chambers under control (90-95\% RH, subgroup 1) or dehydrating (30-35\% RH, subgroup 2) conditions. Samples were collected at harvest (freshly harvested fruit, $\mathrm{FH}$ ), and the ABA-treated and untreated fruit were left for 1 and 3 weeks in the control or dehydrating environments ( 9 different conditions). For all the conditions, four biological replicates, each consisting of five fruit, were used for the wax content and composition analyses. Three additional biological replicates of 10 fruit each per condition were used to take fruit firmness and weight loss measurements. For all the conditions, three biological replicates of five fruit each were employed to determine cuticle thickness and permeability, and to collect flavedo samples, which were frozen and homogenized in liquid nitrogen, and kept at $-80{ }^{\circ} \mathrm{C}$ for the $\mathrm{ABA}$ and gene expression analyses. Therefore, all nine samples composing the experimental design consisted of 65 fruit each.

\subsection{Cuticular Wax Analysis}

Epicuticular waxes from intact fruit of known surface areas were extracted by dipping fruit for $1 \mathrm{~min}$ in two successive chloroform baths, the first of which contained $100 \mu \mathrm{g}$ of tetracosane as the internal standard. Waxes were derivatized using BSTFA and resuspended in $100 \mu \mathrm{L}$ of chloroform after the evaporation of excess BSTFA, as previously described [43]. Wax extracts were injected into a gas chromatograph (GC) 7890B system (Agilent) equipped with an HP-5MS UI $(30 \mathrm{~m} \times 250 \mu \mathrm{m} \times 0.25 \mu \mathrm{m})$ column (Agilent Technologies, Santa Clara, CA, USA) and a 5977A simple quadrupole detector (Agilent Technologies) at the SCSIE-UV Gas Chromatography Facility (Valencia, Spain) following the conditions in [8]. Briefly, the oven temperature was held at $70{ }^{\circ} \mathrm{C}$ for $2 \mathrm{~min}$ before being raised by $10^{\circ} \mathrm{C} \mathrm{min}$ m $^{-1}$ to $200{ }^{\circ} \mathrm{C}$, by $3^{\circ} \mathrm{C} \min ^{-1}$ to $300{ }^{\circ} \mathrm{C}$ and finally held for $20 \mathrm{~min}$. The injector temperature was 
$250{ }^{\circ} \mathrm{C}$. The comparison of the relative retention times with those of commercial standards was used to identify most of the wax components. Computer matching against commercial (Nist, wiley7n) libraries and by MS literature data was also used for identification.

\subsection{Cuticle Permeability and Thickness}

Peel disks of $3 \mathrm{~cm}$ diameter were excised from the equatorial zone of intact fruit. Cuticles were enzymatically isolated and their permeability was measured in gravimetric chambers as described in detail in [8]. Briefly, isolated cuticles were placed face-up in 3D-printed chambers which exposed a constant cuticle surface area, which acted as the only separation barrier between the known amount of water inside the chamber and the dehydrating environment of a desiccation container $\left(25^{\circ} \mathrm{C}, 0 \% \mathrm{RH}\right)$. Folded chambers were stored for up to 1 week and weight loss was measured daily. Cuticle permeability was estimated as the weight loss per hour and per unit of cuticle surface area. At the end of the assay, the integrity of cuticles was verified by $0.01 \%$ aqueous solution $(w / v)$ of Toluidine Blue O (Merck, Darmstadt, Germany) staining. One disk of all five fruit, composing a biological replicate per sample, was used to obtain the isolated cuticles, and three biological replicates per sample were analyzed. Cuticle thickness was determined by light microscopy. Pericarp cubes were excised from fruit, and tissue fixation and embedding were performed as in [9]. A solution of Oil Red O (Alfa Aesar, Kandel, Germany) in isopropyl alcohol was applied to $10 \mu \mathrm{m}$ sections. The stained slides were visualized under an Eclipse 90i Nikon microscope (Nikon corporation, Tokyo, Japan) with a 40X objective and which used the Nis Elements BR 3.2 software (Nikon corporation, Japan). The distance between the outer cuticle part and the top of the most external epidermal cell was used to measure cuticle thickness by the Fiji software (ImageJ 1.49q Software, National Institutes of Health, Bethesda, MD, USA), as previously described by [8]. One pericarp cube from the equatorial zone of all five fruit, composing a biological replicate per sample, was excised, and three biological replicates per sample were analyzed. About five measurements were taken in each section (roughly 75 values per sample).

\subsection{ABA Analysis}

As previously described [51], ABA was extracted from $1 \mathrm{~g}$ of fresh weight frozen flavedo with $80 \%$ acetone, containing $0.5 \mathrm{~g} \mathrm{~L}^{-1}$ of citric acid and $100 \mathrm{mg} \mathrm{L}^{-1}$ of butylated hydroxytoluene. After centrifuging, the supernatant was three-serial diluted in ice-cold TBS (6.05 $\mathrm{g}$ Tris, $8.8 \mathrm{~g} \mathrm{~L}^{-1}$ of $\mathrm{NaCl}$ and $0.2 \mathrm{mg} \mathrm{L}^{-1}$ of $\mathrm{Mg} \mathrm{Cl}_{2}, \mathrm{pH} 7.8$ ) and three samples for each dilution were analyzed by indirect ELISA.

\subsection{Fruit Weight Loss and Firmness Determinations}

During storage, Pinalate fruit were weighed daily to determine the amount of water loss. Fruit cumulative weight loss was calculated as the amount of water loss per surface area. Fruit surface area was determined by measuring three diameters per fruit for every biological replicate. Fruit firmness was analyzed as in [73] with minor modifications. Fruit compression resistance, based on a $5 \mathrm{~mm}$ deformation at two points of the fruit equator, was measured by a 4502 Instron Testing Machine (Instron).

\subsection{Clustering Analysis}

A hierarchical cluster analysis (HCA) was performed to group the different conditions in the experimental design according to their similarities in terms of both cuticle composition and properties in addition to the measured fruit physiological parameters. Average linkage clustering and Euclidian distance methods were followed to plot the dendrogram and heatmap (www.heatmapper.ca (accessed on 5 April 2021)).

\subsection{RNA Extraction, cDNA Synthesis and RT-qPCR}

RNA extraction, cDNA synthesis and RT-qPCR were performed following previously described well-established protocols [50]. Total RNA was isolated from flavedo samples, 
and $2 \mu \mathrm{g}$ were used for the first-strand cDNA synthesis with the "Maxima H Minus First Strand cDNA Synthesis kit with dsDNase" (Thermo Scientific). The specific primer pairs for the genes of interest (CSCER3, CSCER4/FAR3, CsCER6/KCS6, CSSQS, CSABCG11/WBC11, CsABCG12/WBC12, CsCD2 and CsCER7) and those employed for data normalization (Cs$A C T$ and CsTUB) (Supplementary Materials Table S1) were mixed with SYBR Green to monitor cDNA amplification in a LyghCycler480 System (Roche Diagnostic). Amplicon specificity was determined by a melting curve analysis. Fold change relative gene expression values of the target genes were obtained by the Relative Expression Software Tool (REST, rest.gene-quantification.info), as previously described in [50]. Three independent biological replicates and two technical replicates were performed per sample.

\subsection{Statistical Analyses}

Statistical analyses were performed using the INFOSTAT software. Data of the parametric variables were subjected to an analysis of variance (ANOVA), and the significance of differences was determined by Tukey's test $(p<0.05)$ on the mean values. Correlation analyses, carried out with the R software, established the relations among wax fractions and components, cuticle properties and fruit quality parameters. The statistical significance of the positive and negative correlations was considered at $p<0.05$.

Supplementary Materials: The following are available online at https:/ /www.mdpi.com/article/10 .3390/ijms221910242/s1, Table S1: Primers used for qPCR analysis.

Author Contributions: Conceptualization, P.R. and M.T.L.; formal Analysis, P.R.; funding acquisition, P.R. and M.T.L.; investigation, P.R.; methodology, P.R.; project administration, P.R.; software, P.R.; supervision, P.R. and M.T.L.; visualization, P.R.; writing-original draft, P.R.; writing-review and editing, P.R. and M.T.L. Both authors have read and agreed to the published version of the manuscript.

Funding: This research was funded by the 3F: FutureFreshFruit Project as part of the Marie SkłodowskaCurie Actions and the European Horizon 2020 programme, grant number H2020-MSCA-IF-656127.

Acknowledgments: The technical assistance of R. Sampedro is gratefully acknowledged. We also thank G. Ancillo (IVIA) for allowing us to use the Spanish Citrus Germplasm Bank.

Conflicts of Interest: The authors declare no conflict of interest.

\section{References}

1. Ohkuma, K.; Lyon, J.L.; Addicott, F.T.; Smith, O.E. Abscisin II, an abscission-accelerating substance from young cotton fruit. Science 1963, 142, 1592-1593. [CrossRef]

2. Addicott, F.T.; Lyon, J.L.; Ohkuma, K.; Thiessen, W.E.; Carns, H.R.; Smith, O.E.; Cornforth, J.W.; Milborrow, B.V.; Ryback, G.; Wareing, P.F. Abscisic acid: A new name for Abscisin II (Dormin). Science 1968, 159, 1493. [CrossRef] [PubMed]

3. Nakashima, K.; Yamaguchi-Shinozaki, K.; Shinozaki, K. The transcriptional regulatory network in the drought response and its crosstalk in abiotic stress responses including drought, cold, and heat. Front. Plant Sci. 2014, 5, 170. [CrossRef] [PubMed]

4. Leng, P.; Yuan, B.; Guo, Y. The role of abscisic acid in fruit ripening and responses to abiotic stress. J. Exp. Bot. 2014, 65, 4577-4588. [CrossRef]

5. Kosma, D.K.; Bourdenx, B.; Bernard, A.; Parsons, E.P.; Lü, S.; Joubès, J.; Jenks, M.A. The impact of water deficiency on leaf cuticle lipids of Arabidopsis. Plant Physiol. 2009, 151, 1918-1929. [CrossRef] [PubMed]

6. Curvers, K.; Seifi, H.; Mouille, G.; de Rycke, R.; Asselbergh, B.; Van Hecke, A.; Vanderschaeghe, D.; Hofte, H.; Callewaert, N.; Van Breusegem, F.; et al. Abscisic acid deficiency causes changes in cuticle permeability and pectin composition that influence tomato resistance to Botrytis cinerea. Plant Physiol. 2010, 154, 847-860. [CrossRef]

7. Wang, J.; Sun, L.; Xie, L.; He, Y.; Luo, T.; Sheng, L.; Luo, Y.; Zeng, Y.; Xu, J.; Deng, X.; et al. Regulation of cuticle formation during fruit development and ripening in 'Newhall' navel orange (Citrus sinensis Osbeck) revealed by transcriptomic and metabolomic profiling. Plant Sci. 2016, 243, 131-144. [CrossRef]

8. Romero, P.; Lafuente, M.T. Abscisic acid deficiency alters epicuticular wax metabolism and morphology that leads to increased cuticle permeability during sweet orange (Citrus sinensis) fruit ripening. Front. Plant Sci. 2020, 11, 1914. [CrossRef]

9. Martin, L.B.B.; Romero, P.; Fich, E.A.; Domozych, D.S.; Rose, J.K.C. Cuticle biosynthesis in tomato leaves is developmentally regulated by abscisic acid. Plant Physiol. 2017, 174, 1384-1398. [CrossRef]

10. Correia, S.; Santos, M.; Glińska, S.; Gapińska, M.; Matos, M.; Carnide, V.; Schouten, R.; Silva, A.P.; Gonçalves, B. Effects of exogenous compound sprays on cherry cracking: Skin properties and gene expression. J. Sci. Food Agric. 2020, 100, $2911-2921$. [CrossRef] [PubMed] 
11. Martin, L.B.B.; Rose, J.K.C. There's more than one way to skin a fruit: Formation and functions of fruit cuticles. J. Exp. Bot. 2014, 65, 4639-4651. [CrossRef]

12. Yeats, T.H.; Rose, J.K.C. The formation and function of plant cuticles. Plant Physiol. 2013, 163, 5-20. [CrossRef]

13. Bhanot, V.; Fadanavis, S.V.; Panwar, J. Revisiting the architecture, biosynthesis and functional aspects of the plant cuticle: There is more scope. Environ. Exp. Bot. 2021, 183, 104364. [CrossRef]

14. Joubès, J.; Domergue, F. Biosynthesis of the Plant Cuticle. In Hydrocarbons, Oils and Lipids: Diversity, Origin, Chemistry and Fate; Springer International Publishing: Berlin, Germany, 2018; pp. 1-19.

15. Lara, I.; Heredia, A.; Domínguez, E. Shelf life potential and the fruit cuticle: The unexpected player. Front. Plant Sci. 2019, 10, 770. [CrossRef]

16. Tafolla-Arellano, J.C.; Báez-Sañudo, R.; Tiznado-Hernández, M.E. The cuticle as a key factor in the quality of horticultural crops Sci. Hortic. 2018, 232, 145-152. [CrossRef]

17. Parsons, E.P.; Popopvsky, S.; Lohrey, G.T.; Lü, S.; Alkalai-Tuvia, S.; Perzelan, Y.; Paran, I.; Fallik, E.; Jenks, M.A. Fruit cuticle lipid composition and fruit post-harvest water loss in an advanced backcross generation of pepper (Capsicum sp.). Physiol. Plant. 2012, 146, 15-25. [CrossRef] [PubMed]

18. Chu, W.; Gao, H.; Chen, H.; Fang, X.; Zheng, Y. Effects of cuticular wax on the postharvest quality of blueberry fruit. Food Chem. 2018, 239, 68-74. [CrossRef]

19. Chai, Y.; Li, A.; Chit Wai, S.; Song, C.; Zhao, Y.; Duan, Y.; Zhang, B.; Lin, Q. Cuticular wax composition changes of 10 apple cultivars during postharvest storage. Food Chem. 2020, 324, 126903. [CrossRef]

20. Saladié, M.; Matas, A.J.; Isaacson, T.; Jenks, M.A.; Goodwin, S.M.; Niklas, K.J.; Xiaolin, R.; Labavitch, J.M.; Shackel, K.A.; Fernie, A.R.; et al. A reevaluation of the key factors that influence tomato fruit softening and integrity. Plant Physiol. 2007, 144, 1012-1028. [CrossRef]

21. Lownds, N.; Banaras, M.; Bosland, P.W. Relationships between postharvest water loss and physical properties of pepper fruit (Capsicum annuum L.). HortScience 1993, 28, 1182-1184. [CrossRef]

22. Tafolla-Arellano, J.C.; Zheng, Y.; Sun, H.; Jiao, C.; Ruiz-May, E.; Hernández-Oñate, M.A.; González-León, A.; Báez-Sañudo, R.; Fei, Z.; Domozych, D.; et al. Transcriptome analysis of mango (Mangifera indica L.) fruit epidermal peel to identify putative cuticle-associated genes. Sci. Rep. 2017, 7, 46163. [CrossRef] [PubMed]

23. Huang, H.; Burghardt, M.; Schuster, A.-C.; Leide, J.; Lara, I.; Riederer, M. Chemical composition and water permeability of fruit and leaf cuticles of Olea europaea L. J. Agric. Food Chem. 2017, 65, 8790-8797. [CrossRef]

24. Diarte, C.; Xavier de Souza, A.; Staiger, S.; Deininger, A.-C.; Bueno, A.; Burghardt, M.; Graell, J.; Riederer, M.; Lara, I.; Leide, J. Compositional, structural and functional cuticle analysis of Prunus laurocerasus L. sheds light on cuticular barrier plasticity. Plant Physiol. Biochem. 2021, 158, 434-445. [CrossRef]

25. Vichi, S.; Cortés-Francisco, N.; Caixach, J.; Barrios, G.; Mateu, J.; Ninot, A.; Romero, A. Epicuticular wax in developing olives (Olea europaea) is highly dependent upon cultivar and fruit ripeness. J. Agric. Food Chem. 2016, 64, 5985-5994. [CrossRef] [PubMed]

26. Belge, B.; Llovera, M.; Comabella, E.; Graell, J.; Lara, I. Fruit cuticle composition of a melting and a nonmelting peach cultivar. J. Agric. Food Chem. 2014, 62, 3488-3495. [CrossRef]

27. Parsons, E.P.; Popopvsky, S.; Lohrey, G.T.; Alkalai-Tuvia, S.; Perzelan, Y.; Bosland, P.; Bebeli, P.J.; Paran, I.; Fallik, E.; Jenks, M.A. Fruit cuticle lipid composition and water loss in a diverse collection of pepper (Capsicum). Physiol. Plant. 2013, 149, 160-174. [CrossRef] [PubMed]

28. Sala, J.M. Content, chemical composition and morphology of epicuticular wax of Fortune mandarin fruits in relation to peel pitting. J. Sci. Food Agric. 2000, 80, 1887-1894. [CrossRef]

29. Domínguez, E.; Fernández, M.D.; Hernández, J.C.L.; Parra, J.P.; España, L.; Heredia, A.; Cuartero, J. Tomato fruit continues growing while ripening, affecting cuticle properties and cracking. Physiol. Plant. 2012, 146, 473-486. [CrossRef]

30. Peschel, S.; Franke, R.; Schreiber, L.; Knoche, M. Composition of the cuticle of developing sweet cherry fruit. Phytochemistry 2007, 68, 1017-1025. [CrossRef] [PubMed]

31. Knoche, M.; Beyer, M.; Peschel, S.; Oparlakov, B.; Bukovac, M.J. Changes in strain and deposition of cuticle in developing sweet cherry fruit. Physiol. Plant. 2004, 120, 667-677. [CrossRef] [PubMed]

32. D'Angeli, S.; Altamura, M. Unsaturated lipids change in olive tree drupe and seed during fruit development and in response to cold-stress and acclimation. Int. J. Mol. Sci. 2016, 17, 1889. [CrossRef] [PubMed]

33. Baker, E.; Bukovac, M.; Hunt, G. Composition of tomato fruit cuticle as related to fruit growth and development. In The Plant Cuticle; Cutler, D., Alvin, K., Price, C., Eds.; London Academic Press: London, UK, 1982; pp. 33-44.

34. Oliveira Lino, L.; Quilot-Turion, B.; Dufour, C.; Corre, M.-N.; Lessire, R.; Génard, M.; Poëssel, J.-L. Cuticular waxes of nectarines during fruit development in relation to surface conductance and susceptibility to Monilinia laxa. J. Exp. Bot. 2020, 71, $5521-5537$. [CrossRef] [PubMed]

35. Cajuste, J.F.; González-Candelas, L.; Veyrat, A.; García-Breijo, F.J.; Reig-Armiñana, J.; Lafuente, M.T. Epicuticular wax content and morphology as related to ethylene and storage performance of 'Navelate' orange fruit. Postharvest Biol. Technol. 2010, 55, 29-35. [CrossRef]

36. El-Otmani, M.; Coggins, C.W.J. Fruit age and growth regulator effects on the quantity and structure of the epicuticular wax of Washington Navel orange fruit. J. Am. Soc. Hortic. Sci. 1985, 110, 371-378. 
37. Li, F.; Min, D.; Song, B.; Shao, S.; Zhang, X. Ethylene effects on apple fruit cuticular wax composition and content during cold storage. Postharvest Biol. Technol. 2017, 134, 98-105. [CrossRef]

38. Curry, E. Effects of 1-MCP applied postharvest on epicuticular wax of apples (Malus domestica Borkh.) during storage. J. Sci. Food Agric. 2008, 88, 996-1006. [CrossRef]

39. Klein, B.; Ribeiro, Q.M.; Thewes, F.R.; de OliveiraAnese, R.; de Candido deOliveira, F.; Santos, I.D.; Ribeiro, S.R.; Donadel, J.Z.; Brackmann, A.; Barin, J.S.; et al. The isolated or combined effects of dynamic controlled atmosphere (DCA) and 1-MCP on the chemical composition of cuticular wax and metabolism of 'Maxi Gala' apples after long-term storage. Food Res. Int. 2020, 140, 109900. [CrossRef]

40. Lara, I. The fruit cuticle: Actively tuning postharvest quality. In Preharvest Modulation of Postharvest Fruit and Vegetable Quality; Siddiqui, M.W., Ed.; Elsevier: Amsterdam, The Netherlands, 2018; pp. 93-120. ISBN 978-0-12-809807-3.

41. Trivedi, P.; Nguyen, N.; Hykkerud, A.L.; Häggman, H.; Martinussen, I.; Jaakola, L.; Karppinen, K. Developmental and environmental regulation of cuticular wax biosynthesis in fleshy fruits. Front. Plant Sci. 2019, 10, 431. [CrossRef] [PubMed]

42. Jetter, R.; Riederer, M. Localization of the transpiration barrier in the epi- and intracuticular waxes of eight plant species: Water transport resistances are associated with fatty acyl rather than alicyclic components. Plant Physiol. 2016, 170, 921-934. [CrossRef]

43. Romero, P.; Rose, J.K.C. A relationship between tomato fruit softening, cuticle properties and water availability. Food Chem. 2019, 295, 300-310. [CrossRef] [PubMed]

44. Brizzolara, S.; Minnocci, A.; Yembaturova, E.; Tonutti, P. Ultrastructural analysis of berry skin from four grapes varieties at harvest and in relation to postharvest dehydration. OENO One 2020, 54, 1121-1131. [CrossRef]

45. Wang, Y.; Mao, H.; Lv, Y.; Chen, G.; Jiang, Y. Comparative analysis of total wax content, chemical composition and crystal morphology of cuticular wax in Korla pear under different relative humidity of storage. Food Chem. 2021, 339, 128097. [CrossRef]

46. Tadeo, F.R.; Cercós, M.; Colmenero-Flores, J.M.; Iglesias, D.J.; Naranjo, M.A.; Ríos, G.; Carrera, E.; Ruiz-Rivero, O.; Lliso, I.; Morillon, R.; et al. Molecular physiology of development and quality of citrus. In Advances in Botanical Research; Academic Press: Cambridge, MA, USA, 2008; Volume 47, pp. 147-223. ISBN 9780123743275.

47. Zhang, Y.-J.; Wang, X.-J.; Wu, J.-X.; Chen, S.-Y.; Chen, H.; Chai, L.-J.; Yi, H.-L. Comparative transcriptome analyses between a spontaneous late-ripening sweet orange mutant and its wild type suggest the functions of ABA, sucrose and JA during citrus fruit ripening. PLoS ONE 2014, 9, e116056. [CrossRef] [PubMed]

48. Lado, J.; Gambetta, G.; Zacarias, L. Key determinants of citrus fruit quality: Metabolites and main changes during maturation. Sci. Hortic. 2018, 233, 238-248. [CrossRef]

49. Terol, J.; Nueda, M.J.; Ventimilla, D.; Tadeo, F.; Talon, M. Transcriptomic analysis of Citrus clementina mandarin fruits maturation reveals a MADS-box transcription factor that might be involved in the regulation of earliness. BMC Plant Biol. 2019, 19, 47. [CrossRef] [PubMed]

50. Romero, P.; Lafuente, M.T.; Rodrigo, M.J. A sweet orange mutant impaired in carotenoid biosynthesis and reduced ABA levels results in altered molecular responses along peel ripening. Sci. Rep. 2019, 9, 9813. [CrossRef]

51. Lafuente, M.T.; Martínez-Téllez, M.A.; Zacarías, L. Abscisic acid in the response of 'Fortune' mandarins to chilling. Effect of maturity and high-temperature conditioning. J. Sci. Food Agric. 1997, 73, 494-502. [CrossRef]

52. Romero, P.; Lafuente, M.; Rodrigo, M.J. The Citrus ABA signalosome: Identification and transcriptional regulation during sweet orange fruit ripening and leaf dehydration. J. Exp. Bot. 2012, 63, 4931-4945. [CrossRef]

53. Romero, P.; Rodrigo, M.J.; Alférez, F.; Ballester, A.-R.; González-Candelas, L.; Zacarías, L.; Lafuente, M.T. Unravelling molecular responses to moderate dehydration in harvested fruit of sweet orange (Citrus sinensis L. Osbeck) using a fruit-specific ABAdeficient mutant. J. Exp. Bot. 2012, 63, 2753-2767. [CrossRef] [PubMed]

54. Romero, P.; Lafuente, M.T.; Alférez, F. A transcriptional approach to unravel the connection between phospholipases $A_{2}$ and D and ABA signal in citrus under water stress. Plant Physiol. Biochem. 2014, 80, 23-32. [CrossRef]

55. Romero, P.; Gandía, M.; Alférez, F. Interplay between ABA and phospholipases $\mathrm{A}_{2}$ and D in the response of citrus fruit to postharvest dehydration. Plant Physiol. Biochem. 2013, 70, 287-294. [CrossRef] [PubMed]

56. Rodrigo, M.J.; Alquezar, B.; Zacarías, L. Cloning and characterization of two 9-cis-epoxycarotenoid dioxygenase genes, differentially regulated during fruit maturation and under stress conditions, from orange (Citrus sinensis L. Osbeck). J. Exp. Bot. 2006, 57, 633-643. [CrossRef] [PubMed]

57. Agustí, J.; Zapater, M.; Iglesias, D.J.; Cercós, M.; Tadeo, F.R.; Talón, M. Differential expression of putative 9-cis-epoxycarotenoid dioxygenases and abscisic acid accumulation in water stressed vegetative and reproductive tissues of citrus. Plant Sci. 2007, 172, 85-94. [CrossRef]

58. Xian, L.; Sun, P.; Hu, S.; Wu, J.; Liu, J.-H. Molecular cloning and characterization of CrNCED1, a gene encoding 9-cisepoxycarotenoid dioxygenase in Citrus reshni, with functions in tolerance to multiple abiotic stresses. Planta 2014, $239,61-77$. [CrossRef]

59. Romero, P.; Rodrigo, M.J.; Lafuente, M.T. Differential expression of the Citrus sinensis ABA perception system genes during postharvest fruit dehydration. Postharvest Biol. Technol. 2013, 76, 65-73. [CrossRef]

60. Rodrigo, M.J.; Marcos, J.F.; Alférez, F.; Mallent, M.D.; Zacarías, L. Characterization of Pinalate, a novel Citrus sinensis mutant with a fruit-specific alteration that results in yellow pigmentation and decreased ABA content. J. Exp. Bot. 2003, 54, 727-738. [CrossRef] 
61. Alférez, F.; Sala, J.M.; Sanchez-Ballesta, M.T.; Mulas, M.; Lafuente, M.T.; Zacarias, L. A comparative study of the postharvest performance of an ABA-deficient mutant of oranges: I. Physiological and quality aspects. Postharvest Biol. Technol. 2005, 37, 222-231. [CrossRef]

62. Rodrigo, M.J.; Lado, J.; Alós, E.; Alquézar, B.; Dery, O.; Hirschberg, J.; Zacarías, L. A mutant allele of $\zeta$-carotene isomerase (Z-ISO) is associated with the yellow pigmentation of the "Pinalate" sweet orange mutant and reveals new insights into its role in fruit carotenogenesis. BMC Plant Biol. 2019, 19, 465. [CrossRef] [PubMed]

63. Koch, K.; Hartmann, K.D.; Schreiber, L.; Barthlott, W.; Neinhuis, C. Influences of air humidity during the cultivation of plants on wax chemical composition, morphology and leaf surface wettability. Environ. Exp. Bot. 2006, 56, 1-9. [CrossRef]

64. Lewandowska, M.; Keyl, A.; Feussner, I. Wax biosynthesis in response to danger: Its regulation upon abiotic and biotic stress New Phytol. 2020, 227, 698-713. [CrossRef] [PubMed]

65. Shaheenuzzamn, M.; Shi, S.; Sohail, K.; Wu, H.; Liu, T.; An, P.; Wang, Z.; Hasanuzzaman, M. Regulation of cuticular wax biosynthesis in plants under abiotic stress. Plant Biotechnol. Rep. 2021, 15, 1-12. [CrossRef]

66. Zarrouk, O.; Pinheiro, C.; Misra, C.S.; Fernández, V.; Chaves, M.M. Fleshy fruit epidermis is a protective barrier under water stress. In Water Scarcity and Sustainable Agriculture in Semiarid Environment; Academic Press: Cambridge, MA, USA, 2018; pp. 507-533. ISBN 9780128131640.

67. Wang, J.; Hao, H.; Liu, R.; Ma, Q.; Xu, J.; Chen, F.; Cheng, Y.; Deng, X. Comparative analysis of surface wax in mature fruits between Satsuma mandarin (Citrus unshiu) and 'Newhall' navel orange (Citrus sinensis) from the perspective of crystal morphology, chemical composition and key gene expression. Food Chem. 2014, 153, 177-185. [CrossRef] [PubMed]

68. Isaacson, T.; Kosma, D.K.; Matas, A.J.; Buda, G.J.; He, Y.; Yu, B.; Pravitasari, A.; Batteas, J.D.; Stark, R.E.; Jenks, M.A.; et al. Cutin deficiency in the tomato fruit cuticle consistently affects resistance to microbial infection and biomechanical properties, but not transpirational water loss. Plant J. 2009, 60, 363-377. [CrossRef] [PubMed]

69. Leide, J.; Hildebrandt, U.; Reussing, K.; Riederer, M.; Vogg, G. The developmental pattern of tomato fruit wax accumulation and its impact on cuticular transpiration barrier properties: Effects of a deficiency in a beta-ketoacyl-coenzyme A synthase (LeCER6). Plant Physiol. 2007, 144, 1667-1679. [CrossRef]

70. Riederer, M.; Schreiber, L. Protecting against water loss: Analysis of the barrier properties of plant cuticles. J. Exp. Bot. 2001, 52, 2023-2032. [CrossRef] [PubMed]

71. Vogg, G.; Fischer, S.; Leide, J.; Emmanuel, E.; Jetter, R.; Levy, A.A.; Riederer, M. Tomato fruit cuticular waxes and their effects on transpiration barrier properties: Functional characterization of a mutant deficient in a very-long-chain fatty acid $\beta$-ketoacyl-CoA synthase. J. Exp. Bot. 2004, 55, 1401-1410. [CrossRef] [PubMed]

72. Kosma, D.K.; Jenks, M.A. Eco-physiological and molecular-genetic determinants of plant cuticle function in drought and salt stress tolerance. In Advances in Molecular Breeding toward Drought and Salt Tolerant Crops; Jenks, M.A., Hasegawa, P.M., Jain, S.M., Eds.; Springer: Dordrecht, The Netherlands, 2007; pp. 91-120.

73. Lafuente, M.T.; Alférez, F.; Romero, P. Postharvest ethylene conditioning as a tool to reduce quality loss of stored mature sweet oranges. Postharvest Biol. Technol. 2014, 94, 104-111. [CrossRef] 